\title{
Studies on hybridization between a Barbary ram (Ammotragus lervia) and domestic ewes (Ovis aries) and nanny goats (Capra hircus)
}

\author{
N. W. Moore, C. R. E. Halnan*, J. J. McKee* and J. I. Watson* \\ Departments of Animal Husbandry and ${ }^{*}$ Veterinary Anatomy, University of Sydney, Sydney, \\ New South Wales 2006, Australia
}

\begin{abstract}
Summary. Six nanny goats and 9 ewes were inseminated with Barbary semen and 4-5 days after insemination 16 hybrid embryos were recovered: 14 were transferred to ewes or nanny goats. Survival of embryos was monitored by return to service after transfer, peripheral plasma progesterone values and by examination at laparotomy.

None of the Barbary ram $\times$ ewe embryos transferred to 4 ewes and 4 nanny goats or the Barbary ram $x$ nanny goat embryos transferred to ewes survived. Of the 4 nanny goat recipients of Barbary ram $\times$ nanny goat embryos one had a resorbed fetus at 7 weeks after transfer, one was pregnant at 7 weeks but failed to produce a young and a third produced a healthy male 155 days after the transfer oestrus.

The karyotype of the hybrid was $2 n=59 X Y$, characterized by a single metacentric chromosome.
\end{abstract}

\section{Introduction}

Hybridization between bovid species has been reported (Gray, 1972) and in most instances the hybrids have resulted from chance natural matings. Hence, with the exception of crosses between domestic sheep and goats (Hancock, 1964; McGovern, 1975, 1976; Moore \& Eppleston, 1977), factors influencing fertilization between species and the fate of hybrid embryos have not been examined in any detail.

There is good evidence to suggest that sheep and goats and the Barbary sheep, or aoudad have a common ancestor (Zeuner, 1963), although Barbary sheep may more closely resemble the goat than the sheep (Geist, 1971). Cytogenetic studies have shown the karyotype of the domestic goat $(2 n=60)$ is similar to that of the Barbary sheep $(2 n=58)$, the major difference being the presence of a single pair of autosomes in the latter resulting from a Robertsonian-type fusion of 2 pairs of acrocentric autosomes found in the goat (Heck, Wurster \& Benirschke, 1968). Moreover, young have been born after natural mating between the Barbary ram and nanny goat (Gray, 1972; Bunch, Rogers \& Foote, 1977), whereas crossing between the Barbary ram and ewes of domestic sheep has been unsuccessful (Benirschke, 1971; Gray, 1972).

This paper reports on studies of fertilization in domestic ewes and nanny goats inseminated with Barbary ram semen, the fate of hybrid embryos transferred to recipient females and the karyotype of a living male hybrid. 


\section{Materials and Methods}

\section{Mating}

Six feral nanny goats and 9 Merino ewes were inseminated with semen collected by electroejaculation from a Barbary ram of the colony of Barbary sheep held at Taronga Zoo Park, Sydney. The feral goats were of mixed breeding (Angora, Cashmere and milch breeds) and had been captured in the north-west of New South Wales, while the Merinos were obtained from commercial flocks.

Immediately after collection the semen was transported at $30^{\circ} \mathrm{C}$ to the laboratory, diluted 1:1 (v/v) with Dulbecco phosphate buffer, $\mathrm{pH} 7.2$, and $0.05 \mathrm{ml}$ diluted semen was injected into the lumen of each uterine horn of the sheep and goat females. The ewes and nanny goats had been treated with 1000-1500 i.u. PMSG to induce superovulation and they were inseminated within $24 \mathrm{~h}$ of the onset of oestrus.

\section{Transfer of embryos}

At 4-5 days after insemination embryos were collected by flushing the oviducts and uterine horns of the donor females with Dulbecco phosphate buffer enriched with $10 \%$ serum of the donor species. The embryos were then transferred singly to the uterine horns of recipient Merino ewes and feral nanny goats which had been detected in oestrus within $24 \mathrm{~h}$ of their respective donors. The recipients were then run with harnessed vasectomized males of their own species and, starting 2 weeks after transfer, jugular vein blood was collected twice weekly for plasma progesterone determinations using a competitive protein-binding technique (Neill, Johansson, Datta \& Knobil, 1967). Blood collections were discontinued 1 week after recipients returned to service. Laparotomies were carried out 5, 7 or 9 weeks after transfer on those recipients that did not return to oestrus.

\section{Cytogenetic studies}

Jugular vein blood was collected from a male and a female member of the Barbary sheep colony, from 2 nanny goats and 2 ewes and from a male Barbary sheep $\times$ nanny goat hybrid 6 months after birth. One of the nanny goats was the donor of the embryo that developed into the living hybrid; the other was his recipient mother. The 2 ewes were selected at random from within the Merino flock. Karyotypes were prepared as described by Halnan $(1976,1977)$ from cultures of blood lymphocytes and a minimum of 30 metaphases from each sample was examined.

\section{Results}

\section{Fertilization}

Of the 154 ova shed by the ewes and nanny goats, 92 were recovered (Table 1). Seventeen of the ova had cleaved and contained 12, or more, cells (Pl. 1, Fig. 1) but there was no obvious

\section{PLATE 1}

Fig. 1. Barbary ram $\times$ nanny goat embryo recovered 5 days after oestrus.

Fig. 2. Barbary ram $\times$ nanny goat hybrid (left) and his recipient nanny goat mother 10 months after birth.

Fig. 3. Metaphase plate of a male Barbary sheep.

Fig. 4. Metaphase plate of the hybrid shown in Fig. 2.

Fig. 5. Karyotype of the hybrid, $2 n=59 X Y$. Note the single large metacentric chromosome at top left and the unpaired autosomal chromosome 3 . 
PLATE 1
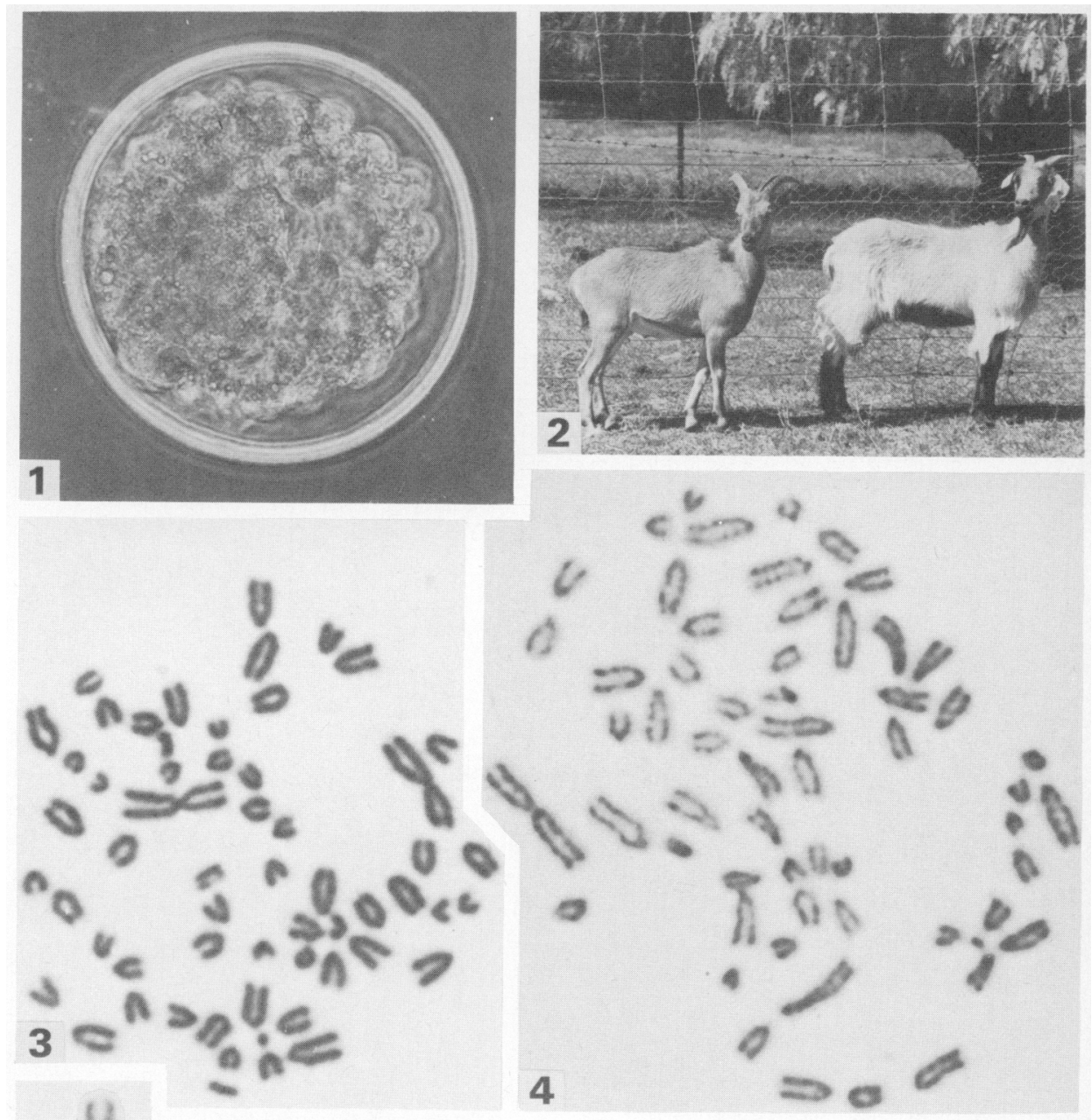

1

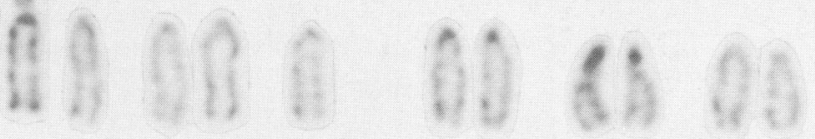

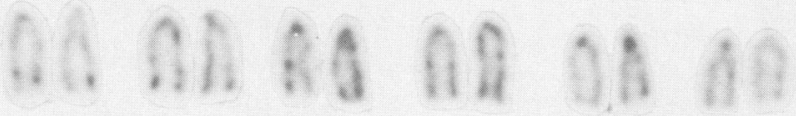

ata thon an aco on

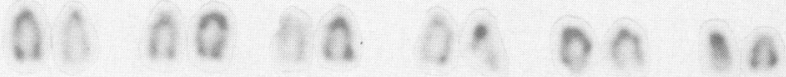

Ae ho ho on a i.

5

(Facing p. 80) 
difference in appearance or cell-stage between embryos of the two crosses. Only uncleaved ova were obtained from 6 ewes and 3 nanny goats.

Table 1. Recovery of embryos from ewes and nanny goats treated with PMSG and inseminated with Barbary ram semen

\begin{tabular}{lcccccc}
\hline & \multicolumn{3}{c}{} & & \multicolumn{2}{c}{$\begin{array}{c}\text { No. of embryos } \\
\text { transferred to }\end{array}$} \\
\cline { 2 - 4 } $\begin{array}{l}\text { No. of females } \\
\text { inseminated }\end{array}$ & Shed & Recovered & Fertilized & & Ewes & $\begin{array}{c}\text { Nanny } \\
\text { goats }\end{array}$ \\
\hline $\begin{array}{l}\text { Nanny goats, } 6 \\
\text { Ewes, } 9\end{array}$ & 46 & 34 & $7^{*}$ & & 2 & 4 \\
\hline
\end{tabular}

* From 3 nanny goats.

† From 3 ewes.

\section{Survival of hybrid embryos}

Fourteen embryos were transferred to recipients (Table 1). However, none of the Barbary ram $\times$ ewe embryos, irrespective of the species of recipient, survived for any appreciable period, and Barbary ram $\times$ nanny goat embryos transferred to ewes also failed to survive. All of the 6 recipient ewes exhibited oestrus between 16 and 18 days after the transfer oestrus, while 3 of the nanny goats receiving Barbary ram $\times$ ewe embryos exhibited oestrus between 19 and 22 days after the transfer oestrus. The remaining nanny goat with a Barbary ram $\times$ ewe embryo failed to exhibit oestrus, but was not pregnant at laparotomy 5 weeks after transfer; peripheral plasma collected 21 and 24 days after the transfer oestrus contained, respectively, 0.2 and $0 \mathrm{ng}$ progesterone $/ \mathrm{ml}$. All ewes and nanny goats which returned to oestrus after transfer had negligible plasma progesterone concentrations on the day of, or 1-2 days after, they exhibited oestrus.

None of the 4 nanny goats that received Barbary ram $\times$ nanny goat embryos exhibited oestrus after transfer. One was not pregnant at laparotomy 5 weeks after transfer and no progesterone was detected in plasma collected 23 days after the transfer oestrus. One had plasma progesterone concentrations of $8 \cdot 2-19.9 \mathrm{ng} / \mathrm{ml}$ up to the time of laparotomy 7 weeks after transfer. At autopsy, carried out immediately after laparotomy, there were resorbing fetal membranes, but no fetus, in the uterus. The third recipient was pregnant at laparotomy at 7 weeks and had plasma progesterone values of $3 \cdot 9-16 \cdot 1 \mathrm{ng} / \mathrm{ml}$ up to 13 weeks after transfer when blood sampling was discontinued. However, she did not give birth and there was no evidence of abortion. At laparotomy 26 weeks after transfer the uterus was small and the ovaries inactive. The remaining doe was pregnant at laparotomies carried out 5 and 9 weeks after transfer, had progesterone concentrations of $4.6-19.6 \mathrm{ng} / \mathrm{ml}$ plasma up to 17 weeks after transfer when collections were discontinued and at 155 days after the transfer oestrus she gave birth to a healthy male (PI. 1, Fig. 2).

\section{Cytogenetic studies}

The karyotypes were $2 \mathrm{n}=60 \mathrm{XX}$ for the nanny goats, $2 \mathrm{n}=54 \mathrm{XX}$ for the ewes, and $2 \mathrm{n}=58 \mathrm{XY}$ and $2 \mathrm{n}=58 \mathrm{XX}$ for the male and female Barbary sheep, respectively (Pl. 1, Fig. 3). The hybrid had a karyotype of $2 \mathrm{n}=59 \mathrm{XY}$ (Pl. 1, Fig. 4 and 5) which was characterized by a single large metacentric autosome and a minute metacentric $\mathrm{Y}$ chromosome.

\section{Discussion}

It is apparent that fertilization of ewe and nanny goat ova by Barbary ram spermatozoa can be achieved and development up to the time at which the embryos were collected (4-5 days after oestrus) proceeded at the same rate as observed in sheep (Trounson \& Moore, 1974) and goat 
embryos (Moore \& Eppleston, 1979). Overall, only some $17 \%$ of the ova collected had cleaved, but there was no evidence of any difference between the two crosses in the ease of achieving fertilization and subsequent development. Uncleaved ova were considered to have been unfertilized, but they were not closely examined for penetration by spermatozoa.

Development of the hybrid embryos up to the time of collection was not influenced by their female parent, but this did not appear to be so of subsequent survival and development. None of 10 embryos in which the ewe was involved, either as dam or recipient, survived for any appreciable time. Time of return to oestrus and plasma progesterone values indicated that corpora lutea regressed at the expected times for non-pregnant ewes and goats. When the nanny goat was involved as dam and recipient, 3 of 4 embryos survived for around 7 weeks or more and the life of the corpus luteum was affected, as judged by high plasma progesterone concentrations.

The karyotypes of the parental animals were as previously described (Basrur \& Coubrough, 1964; Borland, 1964; Basrur \& Stoltz, 1967; Heck et al., 1968) while that of the male hybrid of the Barbary ram $\times$ nanny goat $(2 n=59 X Y)$ is similar, apart from the presence of a metacentric $\mathrm{Y}$ chromosome, to that reported by Bunch et al. (1977) for a female hybrid of the same cross. The karyotype of $2 n=59 X Y$ supports Frechop's (1967) contention that the karyotype of hybrids will be equal to half the sum of the parental diploid numbers. The Barbary sheep karyotype shows two large metacentric autosomes and the goat no metacentrics, whilst the hybrid has a single metacentric (Pl. 1, Figs 3-5) which provides clear evidence of his paternity.

We are indebted to the Director, Taronga Zoo Park, Sydney, for allowing access to the Barbary sheep and in particular to Mr E. P. Finnie and Mr G. L. Reddacliff for their active help and encouragement. The study was supported by a grant from the Australian Research Grants Committee.

\section{References}

Basrur, P.K. \& Coubrough, R.I. (1964) Anatomical and cytological sex of a Saanen goat. Cytogenetics 3, 414-426.

Basrur, P.K. \& Stoltz, D.R. (1967) The Y chromosome of the goat. $J$. Hered. 58, 261-262.

Benirschke, K. (1971) Chimerism, mosaicism and hybrids. In Human Genetics, pp. 212-231. Eds J. de Grouchy, F. J. G. Ebling \& I. W. Henderson. Excerpta Medica, Amsterdam.

Borland, R. (1964) The chromosomes of domestic sheep. J. Hered. 55, 61-64.

Bunch, T.D., Rogers, A. \& Foote, W.C. (1977) G-band and transferrin analysis of Aoudad-goat hybrids. $J$. Hered. 68, 210-212.

Frechop, S. (1967) Hybridisation experiments and relationships between different species of Equidae. Zoo, Antwerp 32, 155-158.

Geist, V. (1971) Mountain Sheep. A Study in Behaviour and Evolution. University of Chicago Press.

Gray, A.P. (1972) Mammalian Hybrids. A Check List with Bibliography. Commonwealth Agricultural Bureau, Slough, England.

Halnan, C.R.E. (1976) Chromosome banding: A modified method for consistent G-banding in cattle, horses and buffaloes. Vet. Rec. 98, 358.

Halnan, C.R.E. (1977) An improved technique for the preparation of chromosomes from cattle whole blood. Res. vet. Sci. 22, 40-43.

Hancock, J.L. (1964) Attempted hybridisation of sheep and goats. Proc. 5th Int. Congr. Anim. Reprod. \& A.I., Trento 3, 445-450.
Heck, H., Wurster, D. \& Benirschke, K. (1968) Chromosome study of members of the subfamilies Caprinae and Bovinae, family Bovidae: the Musk Ox, Ibex, Aoudad, Congo buffalo and Gaur. $Z$. Saugetierk. 33, 172-182.

McGovern, P.T. (1975) The barriers to interspecific hybridisation in domestic and laboratory animals. I. Gametic isolation and hybrid inviability. Br. vet. $J$. 131, 691-706.

McGovern, P.T. (1976) The barriers to interspecific hybridisation in domestic and laboratory animals. II. Hybrid sterility. Br. vet. J. 132, 68-75.

Moore, N.W. \& Eppleston, J. (1977) Inter-species fertilization between sheep and goats. In Reproduction and Evolution, pp. 45-46. Eds J. H. Calaby \& C. H. Tyndale-Biscoe. Aust. Acad. Sci., Canberra.

Moore, N.W. \& Eppleston, J. (1979) Embryo transfer in the Angora goat. Aust. J. agric. Res. 30, 973-981.

Neill, J.D., Johansson, E.D.B., Datta, J.K. \& Knobil, E. (1967) Relationship between plasma levels of luteinizing hormone and progesterone during the normal menstrual cycle. J. clin. Endocr. Metab. 27, 1167-1173.

Trounson, A.O. \& Moore, N.W. (1974) The survival and development of sheep eggs following complete or partial removal of the zona pellucida. J. Reprod. Fert. 41, 97-105.

Zeuner, F.E. (1963) A History of Domesticated Animals. Hutchinson \& Company, London. 